Adv. Geosci., 10, 31-37, 2007

www.adv-geosci.net/10/31/2007/

(C) Author(s) 2007. This work is licensed

under a Creative Commons License.

\title{
Comparison of East Asian winter monsoon indices
}

\author{
Gao Hui \\ Laboratory of Climate Study, Beijing Climate Center, China \\ Received: 30 July 2006 - Revised: 15 December 2006 - Accepted: 16 January 2007 - Published: 26 April 2007
}

\begin{abstract}
Four East Asian winter monsoon (EAWM) indices are compared in this paper. In the research periods, all the indices show similar interannual and decadal-interdecadal variations, with predominant periods centering in 3-4 years, 6.5 years and 9-15 years, respectively. Besides, all the indices show remarkable weakening trends since the 1980s. The correlation coefficient of each two indices is positive with a significance level of $99 \%$.

Both the correlation analyses and the composites indicate that in stronger EAWM years, the Siberian high and the higher-level subtropical westerly jet are stronger, and the Aleutian low and the East Asia trough are deeper. This circulation pattern is favorable for much stronger northwesterly wind and lower air temperature in the subtropical regions of East Asia, while it is on the opposite in weaker EAWM years. Besides, EAWM can also exert a remarkable leading effect on the summer monsoon. After stronger (weaker) EAWM, less (more) summer precipitation is seen over the regions from the Yangtze River valley of China to southern Japan, while more (less) from South China Sea to the tropical western Pacific.
\end{abstract}

\section{Introduction}

Monsoon circulation is an important component of the global circulation system. In the monsoon regions, the local weather and climate are strongly influenced by the anomalous monsoon circulation. Therefore, it is necessary to define a monsoon intensity index in a certain monsoon region in order to examine the multi-scale variations of the monsoon circulation, to explore its relationship with other systems, to seek its internal and external forcings, and to estimate the simulation skills of monsoon variabilities by numerical models. For East

Correspondence to: Gao Hui

(gaohui@cma.gov.cn)
Asian monsoon, many studies have defined and discussed various indices to describe its intensity owing to its importance in the Asian-Australian monsoon system. But most of these indices focused on the East Asian summer monsoon (EASM) only (Gao and Liang, 2005). Comparison of the summer monsoon indices shows that it is hard to provide a unique EASM index (Gao and Zhang, 2003; Wu and Liang, 2003; Jiang and Zai, 2005).

As explored by previous studies (Lau and Li, 1984; Chen et al., 1991; Jhun and Lee, 2004), the main members of East Asian winter monsoon (hereafter, EAWM) circulation are characterized by the Siberian high and the Aleutian low in the sea level pressure (SLP) field, the deep trough in the middle-higher level over the East Asian region, the predominant northwesterlies over northeastern Asia in the lower troposphere, and the strong westerly jet stream centers at southern Japan at higher level.

As the most important circulation system in the boreal winter in East Asia, EAWM directly influences the climate of this region. In recent years, to define an EAWM index has been one of the subjects of monsoon studies. Those indices are generally based on the intensity of one or several members of the winter monsoon circulations, such as the landsea pressure differences (Shi, 1996), the regional averaged meridional wind in the lower troposphere (Ji and Sun, 1997; Chen et al., 2001), zonal wind in higher troposphere (Jhun and Lee, 2004), or the East Asia trough (Sun and Sun, 1995). Detailed definitions of these indices will be introduced in the following section. Undoubtedly, each of those indices can only well represent the anomalous pattern of the EAWM circulation partly. As we know, EAWM is a deeper circulation system in the whole troposphere. Do those indices have similar variations in the research period? Do they have close relationships? Is the definition of an EAWM index more or less difficult than the EASM index? The goal of this paper is try to answer these questions through comparisons of several typical indices.

Published by Copernicus GmbH on behalf of the European Geosciences Union. 
Table 1. Variable, definition regions and the meanings of each East Asian winter monsoon index used in this paper.

\begin{tabular}{lllll}
\hline Index & Variable & Regions & $\begin{array}{l}\text { Meanings of the } \\
\text { original index }\end{array}$ & $\begin{array}{l}\text { Modification in } \\
\text { this paper }\end{array}$ \\
\hline$I_{\mathrm{SHI}}$ & SLP & $\begin{array}{l}\left(110^{\circ} \mathrm{E}, 20^{\circ}-50^{\circ} \mathrm{N}\right) \text { and } \\
\left(160^{\circ} \mathrm{E}, 20^{\circ}-50^{\circ} \mathrm{N}\right)\end{array}$ & $\begin{array}{l}\text { Larger (smaller) value, } \\
\text { Stronger (weaker) EAWM }\end{array}$ & No \\
\hline$I_{\mathrm{JHUN}}$ & $U_{300 \mathrm{hPa}}$ & $\begin{array}{l}\left(27.5^{\circ}-37.5^{\circ} \mathrm{N}, 110^{\circ}-170^{\circ} \mathrm{E}\right) \text { and } \\
\left(50^{\circ}-60^{\circ} \mathrm{N}, 80^{\circ}-140^{\circ} \mathrm{E}\right)\end{array}$ & \\
\hline$I_{\mathrm{SUN}}$ & $H_{500 \mathrm{hPa}}$ & $\left(30^{\circ}-45^{\circ} \mathrm{N}, 125^{\circ}-145^{\circ} \mathrm{E}\right)$ & $\begin{array}{l}\text { Larger (smaller) value, } \\
\text { Weaker (stronger) EAWM }\end{array}$ & $\times(-1)$ \\
\hline$I_{\mathrm{CHEN}}$ & $V_{10 \mathrm{~m}}$ & $\left(25^{\circ}-40^{\circ} \mathrm{N}, 120^{\circ}-140^{\circ} \mathrm{E}\right)$ and & & \\
& & $\left(10^{\circ}-25^{\circ} \mathrm{N}, 110^{\circ}-130^{\circ} \mathrm{E}\right)$ & & \\
\hline
\end{tabular}

\section{Data and methods}

The dataset used in this study include the monthly mean reanalysis project of the National Center for Environmental Prediction/National Center for Atmospheric Research (NCEP/NCAR) (Kalnay et al., 1996; Kistler et al., 2001) during 1958-2003 and the Climate Prediction Center (CPC) merged analysis of precipitation (CMAP) (Xie and Arkin, 1996) during 1979-2003.

The correlation method used in this paper is Pearson correlation.

For a stationary $X(t)$ with mean $\bar{X}$, the autocovariance function $r_{X X}(u)$ and the autocorrelation function $\rho_{X X}(u)$ are functions of lag $u$; that is,

$r_{x x}(u)=E\{[X(t)-\bar{X}][X(t+u)-\bar{X}]\}$

and

$\rho_{X X}(u)=r_{X X}(u) / r_{X X}(0)$.

The power spectrum $\Gamma_{X X}(\omega)$ of process $X(t)$ is the Fourier transform of the autocovariance function; that is,

$\Gamma_{X X}(\omega)=\frac{1}{\pi} \int_{-\infty}^{\infty} r_{X X}(u) e^{-i \omega u} d u$.

The power spectrum curve shows how the variance of the process is distributed with frequency. The variance of a process contributed by frequencies in the range of $\omega$ to $\omega+d \omega$ is given by the area under the power spectrum curve between $\omega$ and $\omega+d \omega$. A peak in the power spectrum is an indication of an important frequency band. A detailed description can be found in Joseph (1973).

\section{EAWM indices}

Based on these circulation systems, several EAWM indices have been suggested. 1) In terms of land-sea thermal differences or pressure differences. For example, Shi (1996) used $\left[\sum_{\text {lat }=20^{\circ} \mathrm{N}}^{50^{\circ} \mathrm{N}}\left(\mathrm{SLP}_{\mathrm{lat}, 110^{\circ} \mathrm{E}}^{*}-S L P_{\text {lat }, 160^{\circ} \mathrm{E}}^{*}\right]^{*}\right.$ as the index (hereafter, $\left.I_{\mathrm{SHI}}\right)$. Where, the “*” denotes the normalization. 2) In terms of regionally averaged meridional wind at lower level. Considering the distinctness between subtropical and tropical winter monsoons, Chen et al. (2001) regarded the difference of 10-meter meridional wind between the region $\left(25^{\circ}-40^{\circ} \mathrm{N}, 120^{\circ}-140^{\circ} \mathrm{E}\right)$ and the region $\left(10^{\circ}-25^{\circ} \mathrm{N}, 110^{\circ}\right.$ $\left.130^{\circ} \mathrm{E}\right)$ as the index $\left(I_{\mathrm{CHEN}}\right) .3$ ) In terms of upper-level zonal wind. Based on the upper westerly jet over East Asia, Jhun and Lee (2004) employed the difference of $300 \mathrm{hPa}$ zonal wind between the region $\left(27.5^{\circ}-37.5^{\circ} \mathrm{N}, 110^{\circ}-170^{\circ} \mathrm{E}\right)$ and the region $\left(50^{\circ}-60^{\circ} \mathrm{N}, 80^{\circ}-140^{\circ} \mathrm{E}\right)$ as the index $\left.\left(I_{\mathrm{JHUN}}\right) .4\right)$ In terms of East Asian Trough. Sun and Sun (1997) used the regional mean of $500 \mathrm{hPa}$ geopotential height $(\mathrm{GPH})$ over the region $\left(0^{\circ}-45^{\circ} \mathrm{N}, 125^{\circ}-145^{\circ} \mathrm{E}\right)$ as the index $\left(I_{\mathrm{SUN}}\right)$.

From the original definitions of these indices one can see that larger (smaller) value means stronger (weaker) EAWM for $I_{\mathrm{SHI}}$ and $I_{\mathrm{JHUN}}$, but weaker (stronger) EAWM for $I_{\mathrm{SUN}}$ and $I_{\mathrm{CHEN}}$. So in the following analyses, the signs of both $I_{\text {SUN }}$ and $I_{\text {CHEN }}$ are reversed by multiplying $(-1)$ for consistency.

Table 1 describes the variables, definition regions and the meanings of each EAWM index used in this paper.

\section{Variations of EAWM}

From the annual curves of each index and its interannual $(\leq 7$ years) and decadal-interdecadal ( $>8$ years) components one can find that the indices show similar variations (Fig. 1). In the research periods, there are 12 (13) years in which all the four indices are positive (negative), which means that each index can depict the anomalous pattern of the EAWM circulations. And significant weakening trends can be clearly seen in the indices since the 1980s. Power spectrum analyses (Fig. 2) of each index show the most predominant interannual period centers in 3-4 years (Chen et al., 1991), the secondary period nears 6.5 years, and the main decadal-interdecadal 

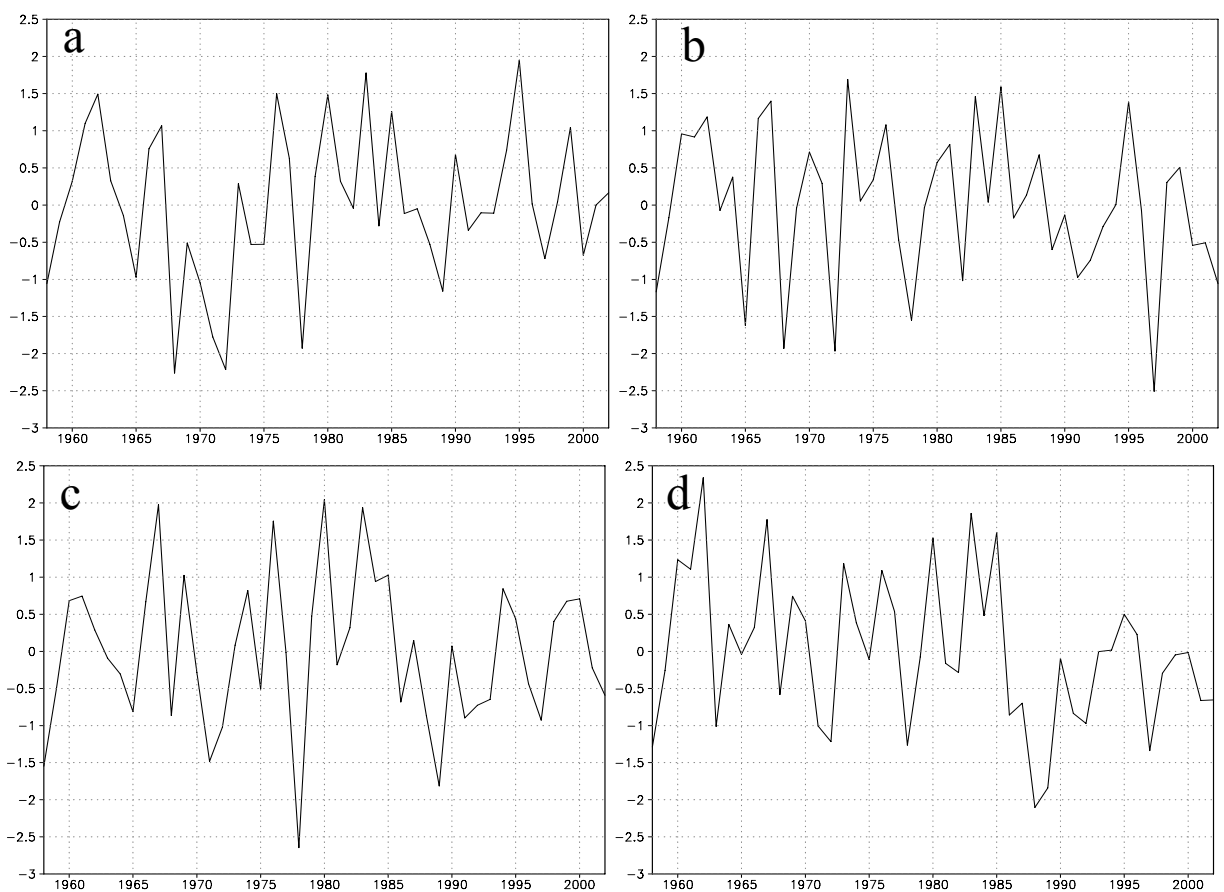

Fig. 1. Time series of the four EAWM indices (a: $\left.I_{\mathrm{SHI}} ; \mathbf{b}: I_{\mathrm{CHEN}} ; \mathbf{c}: I_{\mathrm{JHUN}} ; \mathbf{d}: I_{\mathrm{SUN}}\right)$. The abscissa means the year.
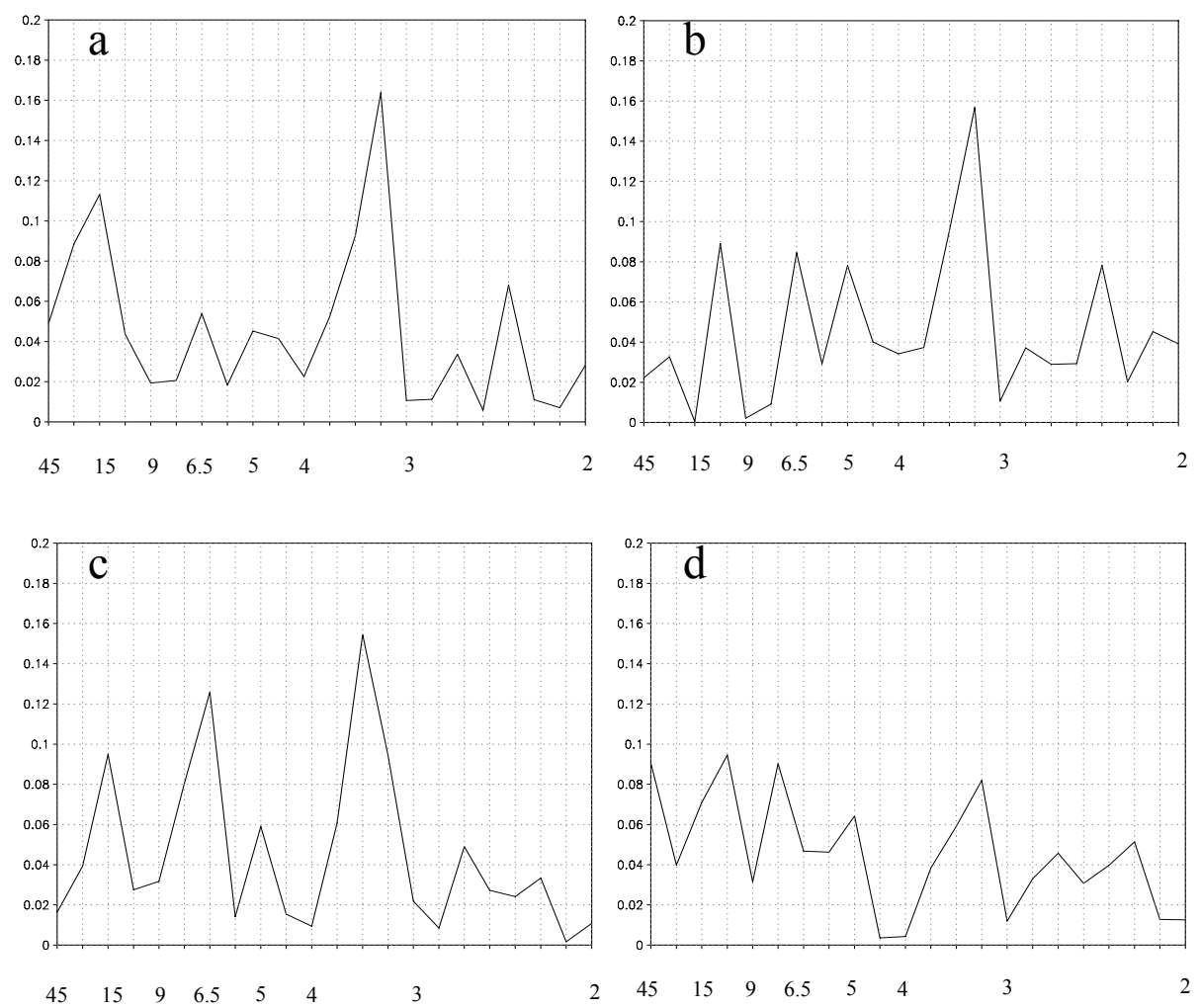

Fig. 2. Power spectra of the four EAWM indices (a: $\left.I_{\mathrm{SHI}} ; \mathbf{b}: I_{\mathrm{CHEN}} ; \mathbf{c}: I_{\mathrm{JHUN}} ; \mathbf{d}: I_{\mathrm{SUN}}\right)$. The abscissa means the period (unit: year). 
Table 2. Correlation coefficients of the EAWM indices. The values outside, on the left side and on the right side of each pair of the parentheses are the coefficients of the original indices, their decadal-interdecadal and interannual components, respectively. Each of the coefficients has passed the $99 \%$ significance level.

\begin{tabular}{lllll}
\hline & $I_{\mathrm{SHI}}$ & $I_{\mathrm{CHEN}}$ & $I_{\mathrm{JHUN}}$ & $I_{\mathrm{SUN}}$ \\
\hline$I_{\mathrm{SHI}}$ & 1.00 & $0.71(0.42,0.82)$ & $0.75(0.60,0.83)$ & $0.68(0.46,0.79)$ \\
$I_{\mathrm{CHEN}}$ & & 1.00 & $0.63(0.68,0.60)$ & $0.68(0.71,0.69)$ \\
$I_{\mathrm{JHUN}}$ & & & 1.00 & $0.79(0.83,0.74)$ \\
$I_{\text {SUN }}$ & & & & 1.00 \\
\hline
\end{tabular}

period locates in $9-15$ years, which is consistent with the results of Jhun and Lee (2004). But the quasi-biennial oscillation (QBO) explored in earlier studies (Guo, 1987; Xu et al., 1999) can hardly be found in the spectrum results.

Table 2 shows the correlation coefficients of each pair of the four EAWM indices. The values outside, on the left side and on the right side of each pair of the parentheses are the coefficients of the original indices, their decadal-interdecadal and interannual components, respectively. Obviously, all the coefficients have passed the $99 \%$ significance level, which also means these indices undergo similar interannual and decadal-interdecadal variations. The coefficients are greater than those of the EASM indices (Gao and Zhang, 2001, Table 1).

In the following section, first we select the stronger EAWM years when the standardized value of each index is greater than 0.5 and the weaker EAWM years when the standardized value is less than -0.5 . The composite analysis is then used to obtain the anomalous general characteristics for stronger and weaker EAWMs. The six stronger EAWM years are 1961/62, 1967/68, 1976/77, 1980/81, 1983/84 and 1985/86; the six weaker years are 1958/59, 1968/69, $1972 / 73,1978 / 79,1989 / 90$ and 1997/98.

\section{Comparison of the relationships between each index and EAWM circulations}

Figures 3-5 show the correlation coefficients between each EAWM index and the SLP (Fig. 3), $500 \mathrm{hPa}$ GPH (Fig. 4) and the surface air temperature (Fig. 5). From Fig. 3 one can see there is a positive center over the Siberian high and a negative center over the Aleutian low and both the coefficients have passed the $95 \%$ significance level. There is also a significant negative center over the Intertropical Convergence Zone (ITCZ) in Fig. 3b and Fig. 3d, but not so remarkable in the other two figures. This correlation pattern indicates that the Siberian high will be stronger (weaker) in stronger (weaker) EAWM years, and the Aleutian low and the ITCZ will be deeper (shallower).

In the correlation maps with $500 \mathrm{hPa} \mathrm{GPH}$, the coefficients are also significantly negative over the East Asian Trough
(EAT) regions, which means the EAT will be deeper (shallower) in stronger (weaker) EAWM years (Fig. 4).

In the correlation maps with surface air temperature, negative values can be seen over the subtropical regions of East Asia (Fig.5), especially from eastern China to Japan, i.e., over $\left(20^{\circ}-45^{\circ} \mathrm{N}\right)$, with coefficients over the $95 \%$ significance level. But in the tropical regions of East Asia, the negative values are rather less. So the influences of EAWM on surface air temperature are mainly limited in the subtropical regions. Results (not shown) of the composed 2-meter temperature by NCEP/NCAR and China observational data are consistent with Fig. 5.

As explored by Webster et al. (1998), “...the dry of the winter monsoon is tied to the wet of the summer monsoon and vice versa...", besides the simultaneous relations, the EAWM has also great leading influences on the EASM circulations, especially on the summer precipitation over East Asia. This has been examined both by observations (Yan et al., 2003) and numerical experiments (Yang et al., 2005). In this analysis, both the correlation and the composites indicate that after stronger (weaker) EAWM, less (more) summer precipitation will be seen over the regions from the Yangtze River valley of China to southern Japan, but more (less) precipitation from South China Sea to the tropical western Pacific (figures not shown).

\section{Conclusions}

Monsoon circulation is an important component of the global circulation systems. Based on the monthly NCEP/NCAR reanalysis project and CMAP data, four typical EAWM indices based on the main members of EAWM circulation systems are compared in this paper. Results show that all the indices show similar interannual and decadal-interdecadal variations. Most indices have significant weakening trends since the 1980s. The correlation coefficient of each pair of the indices is positive with a significance level of $99 \%$. In the research periods, there are 12 (13) years in which all the four indices are positive (negative). Power spectrum results of each index show the most predominant interannual period in 3-4 years, the secondary near 6.5 years, and the main decadal-interdecadal period in $9-15$ years. 

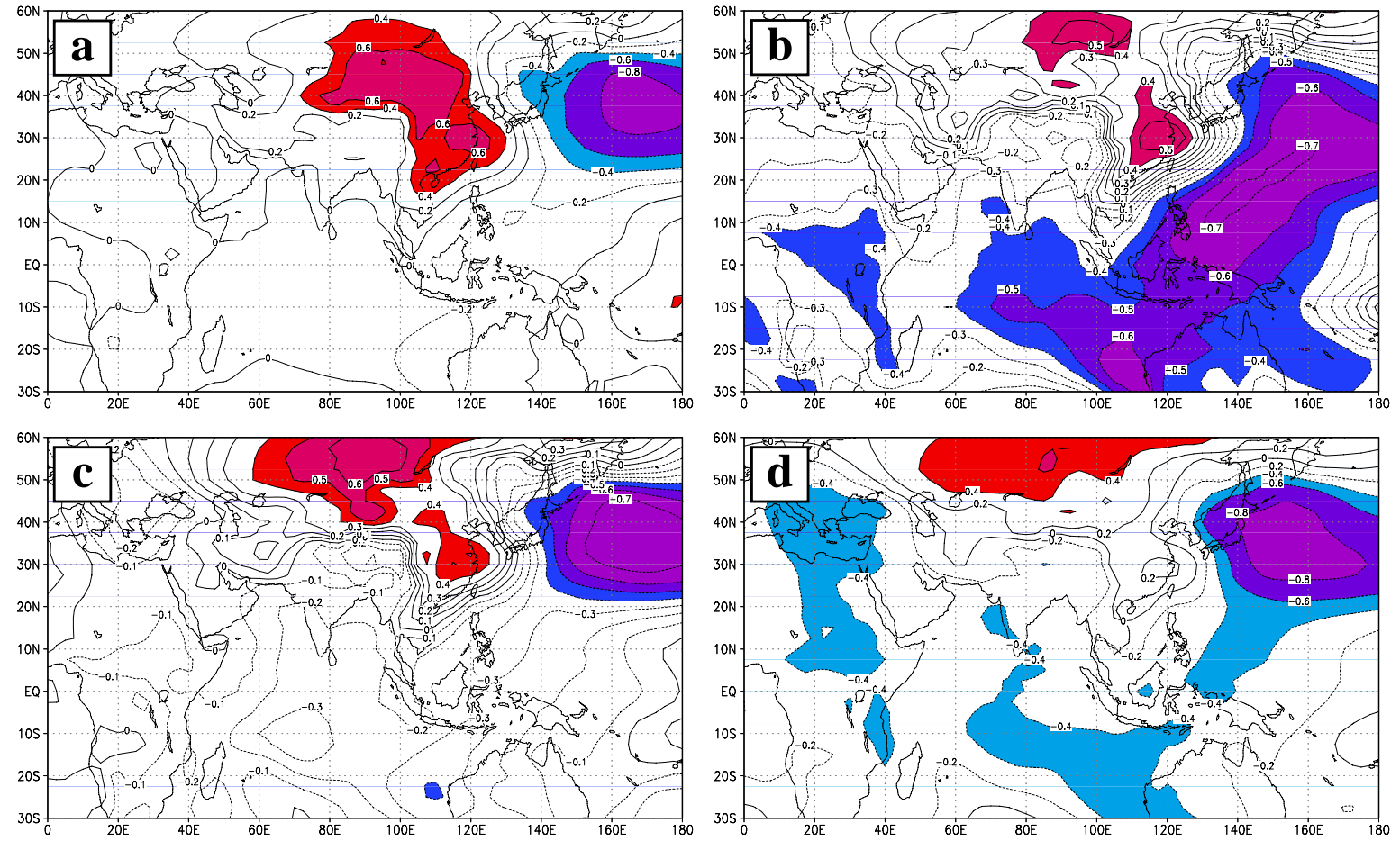

Fig. 3. Correlation coefficients of each index with SLP (a: $\left.I_{\mathrm{SHI}} ; \mathbf{b}: I_{\mathrm{CHEN}} ; \mathbf{c}: I_{\mathrm{JHUN}} ; \mathbf{d}: I_{\mathrm{SUN}}\right)$. Shaded regions mean the $95 \%$ significance level.
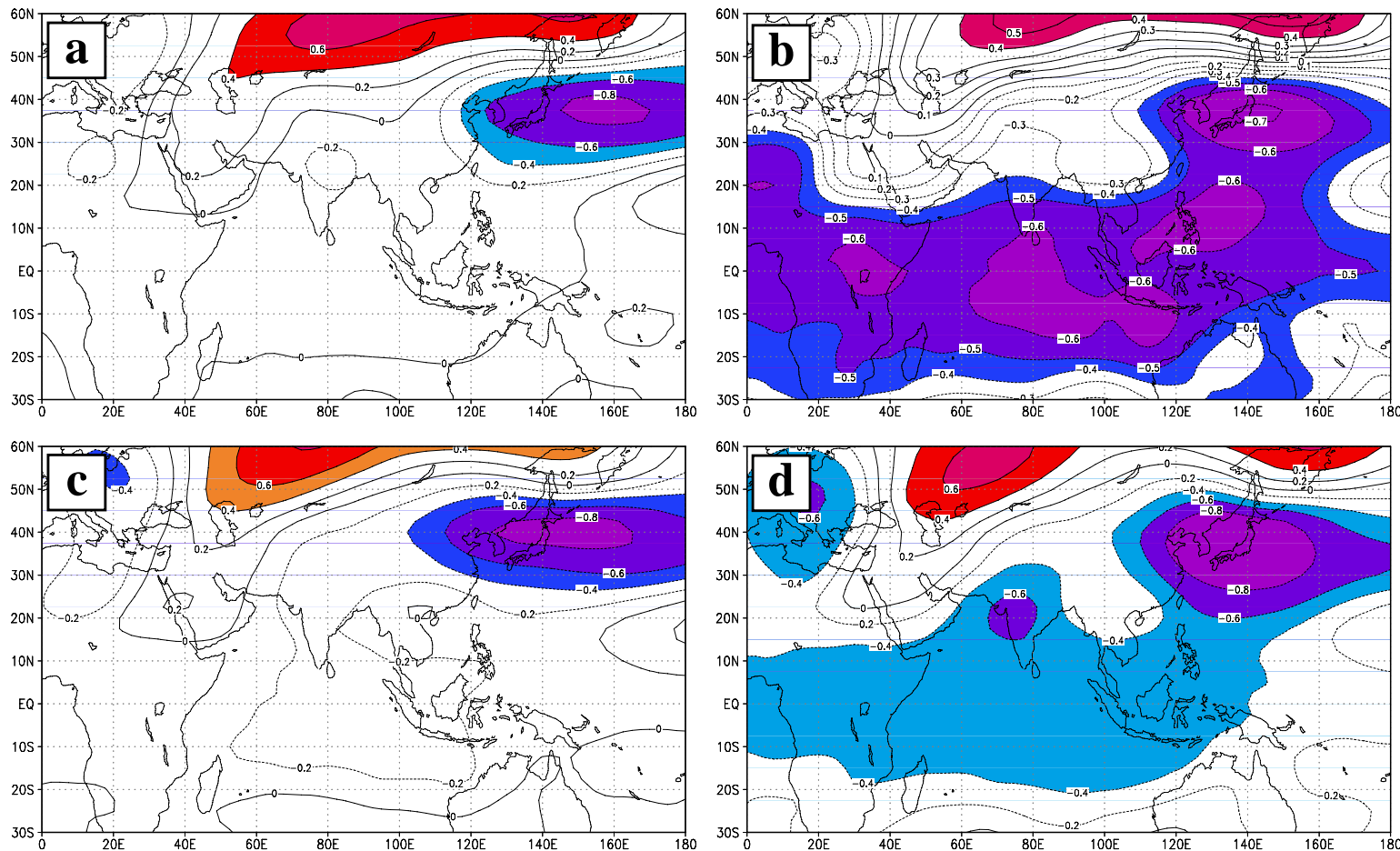

Fig. 4. The same as Fig. 3, but with $500 \mathrm{hPa} \mathrm{GPH}$. 



Fig. 5. The same as Fig. 3, but with surface air temperature.

Results also indicate that when EAWM is stronger, both the Siberian high and the higher-level subtropical westerly jet are stronger, and the Aleutian low and the East Asia trough are deeper than normal. This pattern is favorable for stronger northwesterly wind and lower air temperature in the subtropical regions of East Asia, while it is on the opposite in weaker EAWM years. After stronger (weaker) EAWM, less (more) summer precipitation will be seen over the regions from the Yangtze River valley of China to southern Japan and more (less) from South China Sea to the tropical western Pacific. Therefore, the EAWM has a remarkable leading influence on the following summer monsoon.

Yan et al. (2003) gave a possible explanation of the mechanism of EAWM on EASM through composites of sea surface temperature (SST) and outgoing longwave radiation (OLR) anomalies in stronger and weaker EAWM years. In the stronger EAWM years, the cold surges from the high latitudes are intensified. That causes lower SSTs over the coast regions of East Asia, especially over South China Sea. As we know, the heat content of the ocean is much larger than the atmosphere and the change of SSTs is relatively slower. So even in boreal spring and earlier summer, the SSTs over South China Sea are still lower than normal, so the convections are less active. That means less summer precipitation will occur along the Yangtze River valley. While after the weaker EAWM years, the convection will be stronger than normal in the boreal spring and summer and the summer pre- cipitation belt will be located over the Yangtze River valley longer.

Acknowledgements. The author would like to thank Sun Fengpeng and two anonymous reviewers for their helpful comments and suggestions. This work was supported by the Climate Change Special Foundation of China Meteorological Administration under Grant No. CCSF2007-6.

Edited by: S. C. Michaelides and E. Amitai

Reviewed by: anonymous referees

\section{References}

Chen, L. X., Zhu, Q. G., Luo, H. B., et al.: East Asian Monsoon, Beijing: China Meteorological Press, PP362, 1991.

Chen, W., Graf, H. F., and Huang, R. H.: The interannual variability of East Asian winter monsoon and its relation to the summer monsoon, Adv. Atmos. Sci., 17(1), 48-60, 2001.

Gao, H. and Liang, J. Y.: Definition of South China Sea summer monsoon's onset date and East Asian summer monsoon index, J. Trop. Meteorol., 21(5), 525-532, 2005.

Gao, H. and Zhang,F. H.: Discussion and comparison of East Asian summer monsoon index, J. Trop. Meteorol., 19(1), 79-86, 2003.

Guo, Q. Y.: The East Asian monsoon and the southern oscillation (1871-1980), the climate of China and global climate, Beijing: China Ocean Press, 249-255, 1987.

Kalnay, E. and coauthors: The NCEP/NCAR 40-year reanalysis project, Bull. Amer. Meteor. Soc., 77(3), 437-471, 1996. 
Kistler, R. and coauthors: The NCEP-NCAR 50-year reanalysis: monthly means CD-ROM and documentation, Bull. Amer. Meteor. Soc., 82(2), 247-268, 2001.

Jhun, J. G. and Lee, E. J.: A new East Asian winter monsoon index and associated characteristics of the winter monsoon, J. Climate, 17(4), 711-726, 2004.

Ji, L. R. and Sun, S. Q.: Model Study on the interannual variability of Asian winter monsoon and its influence, Adv. Atmos. Sci., 14(1), 1-22, 1997.

Jiang, Y. and Zhai, P. M.: Correlation between several indices of Asia monsoon and China summer main precipitation patterns, $\mathrm{J}$. Appl. Meteorol. Sci., 16(3), 70-76, 2005.

Jospeh, E. S.: Spectral Analysis of Daily Maximum and Minimum Temperature Series on the East Slope of the Colorado Front Range, Mon. Wea. Rev., 101(6), 505-509, 1973.

Lau, K. M. and Li, M. T.: The monsoon of East Asia and its global associations-A survey, Bull. Amer. Meteorol. Soc., 65(2), 114125, 1984.

Shi, N.: Features of the East Asian winter monsoon intensity on multiple time scale in recent 40 years and their relation to climate, J. Appl. Meteorol. Sci., 7(2), 175-182, 1996.

Sun, S. Q. and Sun, B. M.: The relationship between the anomalous winter monsoon circulation over East Asia and summer drought/flooding in the Yangtze and Huaihe River valley, Acta Meteorological Sinica, 57(4), 513-522, 1995.

Webster, P. J. and Yang, S.: Monsoon and ENSO: selectively interactive systems, Quart. J. Roy. Meteor. Soc., 118, 877-926, 1992.
Webster, P. J., Magana, V. O., Palmer, T. N., Shukla, J., Tomas, R. A., Yanai, M., and Yasunari, T.: Monsoons: processes, predictability, and the prospects for prediction, J. Geophys. Res., 103(C7), 14 451-14 510, 1998.

Wu, S. S., Liang, J. Y., and Li, C. H.: Relationship between the intensity of south china sea summer monsoon and the precipitation in raining seasons in China, J. Trop. Meteorol., 19(Suppl.), 25-36, 2003.

Xie, P. P. and Arkin, P. A.: Analyses of global monthly precipitation using gauge observations, satellite estimates, and numerical model predictions, J. Climate, 9(4), 840-858, 1996.

$\mathrm{Xu}$, J. J., Zhu, Q. G., and Zhou, T. H.: Sudden and periodic changes of East Asian winter monsoon in the past century, J. Appl. Meteorol. Sci., 10(1), 1-8, 1999.

Yan, H. M., Duan, W., and Xiao, Z. N.: A study on the relation between East Asian winter monsoon and climate change during raining season in China, J. Trop. Meteorol., 19(4), 367-376, 2003.

Yang, H., Chen, J., and Sun, S. Q.: Numerical experiment on the interseasonal connection of circulation, Chin. J. Atmos. Sci., 29(3), 396-408, 2005.

Yasunar, T.: A possible link of QBOs between the stratosphere, troposphere and sea surface temperature in the tropics, J. Meteorol Soc. Jpn, 67, 483-493, 1989.

Zhang, Yi., Kenneth, R. S., and James, S. B.: Climatology and interannual variation of the East Asian winter monsoon: Results from the 1979-95 NCEP/NCAR reanalysis, Mon. Wea. Rev., 125(10), 2605-2619, 1997. 